\title{
Erratum to: Microwave-Assisted Synthesis of Copolymers Based on Acrylamide and Allyloxyphenyl-Substituted Porphyrins with Different Functionalities
}

\author{
N. L. Pechnikova ${ }^{a, *}$, I. V. Shilov ${ }^{a}$, A. V. Lyubimtsev ${ }^{a}$, and T. A. Ageeva ${ }^{a}$ \\ ${ }^{a}$ Ivanovo State University of Chemical Technology, Ivanovo, 153000 Russia \\ *e-mail:peclin@mail.ru
}

Received November 2, 2021; revised November 3, 2021; accepted November 3, 2021

DOI: $10.1134 / \mathrm{S} 1070363221100297$

Figure 1 should be as

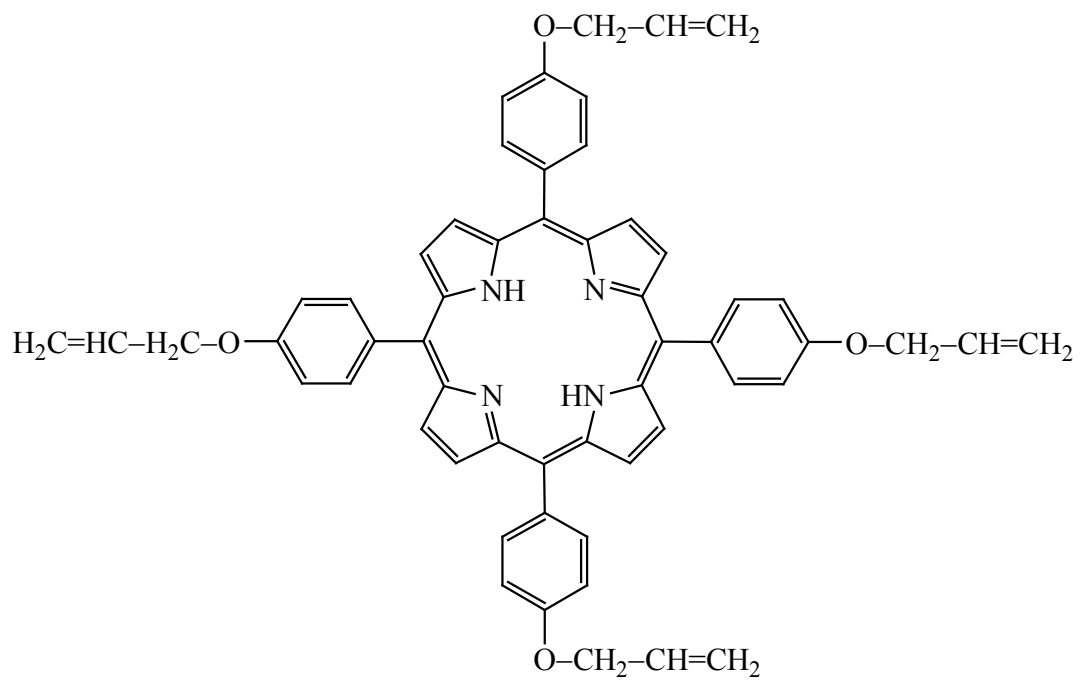

P1

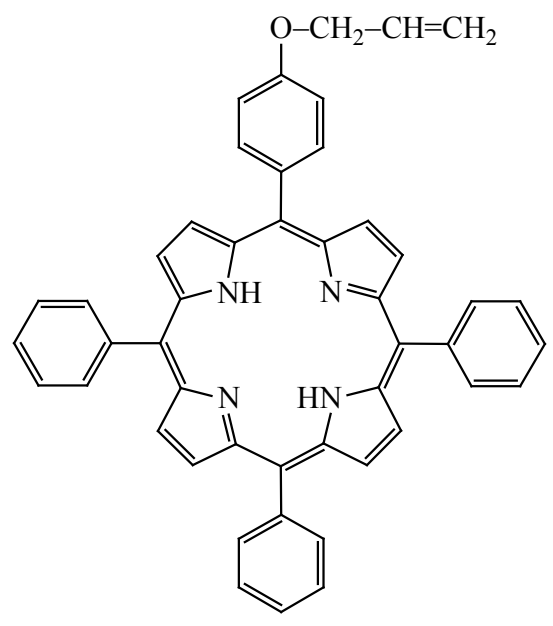

P2

Fig. 1. Structural formulas of the porphyrin monomers $\mathbf{P 1}$ and $\mathbf{P 2}$.

The original article can be found online at https://doi.org/10.1134/S1070363221090309 